\title{
Potential role of N-carbamoyl glutamate in biosynthesis of arginine and its significance in production of ruminant animals
}

\author{
Bahram Chacher ${ }^{1,2}$, Hongyun Liu ${ }^{1,2}$, Diming Wang ${ }^{1,2}$ and Jianxin Liu ${ }^{1,2^{*}}$
}

\begin{abstract}
Arginine (ARG) exerts many beneficial effects on animal body and enhanced angiogenesis, lactogenesis, which finally leads to the improvement in nitrogen $(N)$ metabolism, reproduction, lactation, immunity and growth. Unfortunately, unprotected ARG will be degraded in the rumen and its price is high, thus feeding rumen-protected ARG seems to be uneconomical. Alternatively, N-carbamoyl glutamate (NCG) is structural analogue of N-acetyl glutamate, cofactor of cabamoyl phosphate synthetase1, is lower in rumen degradation compared to ARG. Additionally, rumen epithelial and duodenal cells have potentially utilized the NCG for ureagenesis. Supplementation of NCG to high yielding dairy cows increased plasma concentration of ARG and nitric oxide, decreased the plasma ammonia $\mathrm{N}$ and improved lactation performance and $\mathrm{N}$ utilization. Supplementation of NCG enhanced pregnancy rates in rats, improved litter size and fetal survival rate, thereby improved the reproductive performance of sows. Oral NCG supplementation increases plasma ARG and somatotropin levels, and increased growth rate and muscle protein synthesis in nursing piglets. The NCG is potential a relatively cheaper source of feed additive to offer vital compensation over oral administration of ARG, resulting in improved ruminant animal health and production. In this article, we reviewed the mechanism of ARG biosynthesis by NCG and their significance in growth, reproduction, milk production and $\mathrm{N}$ utilization in ruminant animals.
\end{abstract}

Keywords: Arginine, Lactation, N-cabamoyl glutamate, Nitrogen utilization, Pregnancy, Ruminant animals

\section{Introduction}

Supply of all essential and non-essential amino acids (AA) to animals at systemic level is of great importance to assure the demands of AA for both maintenance and production. Arginine (ARG) is one of the most versatile AA, which serves as a precursor for synthesis of urea, nitric oxide $(\mathrm{NO})$ and polyamines and regulates key metabolic pathways that are critical to health, growth, reproduction and homeostasis of the animals [1]. Despite the fact that ruminant can synthesize it, ARG is normally considered to be essential, because denovo synthesis is not sufficient to meet the requirement particularly during the early stages of growth or for high level of production [2] Moreover, ARG is well recognized for functioning of

\footnotetext{
* Correspondence: liujx@zju.edu.cn

'Institute of Dairy Science, College of Animal Sciences, Zhejiang University, 866 Yuhangtang Road, Hangzhou 310058, P R China

${ }^{2}$ MOE Key Laboratory of Molecular Animal Nutrition, Zhejiang University, Hangzhou 310058, People's Republic of China
}

ureagenesis and ammonia detoxification [3]. Generally, high performance animals are offered diets rich in protein, which could impair the ureagenesis and increase the plasma ammonia concentration, resulting in infertility, decreased milk production, increased nitrogen $(\mathrm{N})$ excretion in urine and feces contributing to environmental pollution. Therefore, supplementation of targeted nutrients could improve fertility, milk production and $\mathrm{N}$ utilization in high-producing animals by decreasing plasma ammonia load through efficient regulation of urea cycle.

In the previous studies it has been showed that infusion of ARG could improve the $\mathrm{N}$ metabolism in heifers [4] and milk production in cows [5]. Parenteral administration of ARG in ewes decreased embryonic loss, increased lamb birth weight, and improved survival rate of fetal lamb to term in prolific ewes [6,7]. However, ARG was rapidly degraded in rumen [8], and parental administration of ARG to farm animal is not a practical approach, while feeding of rumen-protected ARG seems

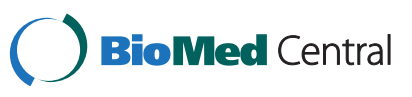


to be uneconomical. N-cabamoyl glutamate (NCG) is a structural analogue of $\mathrm{N}$-acetyl glutamate (NAG) [9], and is low in rumen degradation [8]. Supplementation of NCG increased the endogenous synthesis of plasma ARG in piglets [10]. Oba et al. [11] confirmed that rumen epithelial and duodenal cells could utilize the NCG for urea synthesis. Moreover, feeding NCG to animals seemed to be more beneficial than ARG, because oral administration of NCG rather than ARG entered the systemic circulation completely in adults [12]. Additionally, NCG with low costs is available from chemical synthesis [13]. These advantages indicate that NCG is a possibly cheap source of feed additive that improve the ruminant production and benefit the dairy producers.

Limited information is available on function of NCG in ruminant animals. In this article, we reviewed the mechanism of ARG biosynthesis in which the NCG is involved and their potential function in reproduction, growth, lactation and $\mathrm{N}$ utilization in ruminant animals.

\section{Arginine biosynthesis in which NCG is involved in ruminant animals}

The ARG is an integral constituent of urea cycle, a major pathway for urea synthesis and ammonia detoxification. The biosynthesis of urea is initiated in mitochondria of heptocycte and intestinal cells by the action of cabamoyl phosphate synthetase 1 (CPS I), whose activity is stimulated by NAG. The ARG is a direct allsoteric activator of NAG synthase, a mitochondrial enzyme converting glutamate and acetyl coenzyme A to NAG $[14,15]$. On the other hand, NCG is active but biologically stable structural analogue of NAG [9] that is co-factor of the first rate-limiting enzyme CPS1 [16], while CPS1 remains inactive in the absence of NAG [15]. The NAG is readily hydrolyzed in vivo, while the NCG is stable in both in vivo and in vitro situation and resistant to degradation by aminoacylase. Moreover, NCG can cross the mitochondrial membrane to enter inside [17]. Therefore, ARG can be synthesized endogenously from glutamate via pyrroline-5carboxylate (P5C), ornithine, citrulline, and argininosuccinate. The P5C synthase and NAG synthase are the two key regulatory enzymes in the intestinal citrulline synthesis [16]. Thus, NCG is also called the ARG raiser. Generally, AAs are required for optimal growth, reproduction, lactation and maintenance, but the quantification of proteins and AAs are difficult due to complex rumen metabolism.

In our previous study [8], the proportion of ARG and NCG degradation in rumen fluid for $24 \mathrm{~h}$ was $100.0 \%$ and $17.8 \%$, respectively. Addition of NCG and ARG increased in vitro gas production and acetate to propionate ratio and diminished microbial protein mass compared with the control. Rapid degradation of ARG in rumen is a nutritionally wasteful process. Thus, ARG should be spared from rumen degradation, while NCG could be fed to ruminant without need for coating [8]. Furthermore, NCG is much cheaper than ARG [13]. In addition, NCG has variable advantages over ARG. The NCG does not interfere with intestinal absorption of dietary tryptophan and basic AA, and may result in a balanced ARG during the suckling period due to constant activation of intestinal synthesis of citrulline by NCG. Low dose of NCG is effective in activation of both P5C synthase and CPS-I. Our preliminary results of feeding 20 and $30 \mathrm{~g} / \mathrm{d}$ NCG to high yielding dairy cows indicated an increased plasma ARG concentration [18]. Therefore, NCG is potential feed additive to rise plasma ARG concentration and to enhance ruminant performance.

\section{Significance of NCG in reproduction Conception rate and early embryo loss}

Reproductive efficiency in dairy cows is decreasing worldwide. The increased in milk production per cow is one of contributing factors. Compared with traditional dairy system, the cows in modern intensive farms have longer intervals to first ovulation, higher incidence of anestrous, abnormal luteal phases, higher twinning rates and greater embryonic loss [19]. High yielding dairy cows are usually fed diets rich in crude protein, which consequently elevated plasma urea $\mathrm{N}$ concentration and was associated with decreased fertility in dairy cows because the nitrogenous waste products such as ammonia and urea $\mathrm{N}$ are considered to be toxic in bovine gametes and/or embryos and easily cause reproductive inefficiency in dairy cows [20]. Whereas, high concentration of plasma urea $\mathrm{N}$ in early lactation elevated the ammonia $\mathrm{N}$ and urea $\mathrm{N}$ concentrations in both follicular fluid of pre-ovulatory follicles and uterine fluid during the luteal phase of the estrous cycle [21].

Supplementation of NCG can increase endogenous synthesis of ARG, resulting in increases plasma ARG concentration [9]. It has been indicated that feeding NCG significantly decreased the plasma ammonia $\mathrm{N}$ contents and restore ureagesis in both human and piglets $[9,22]$. Therefore, conception rates of high yielding cows that fed high protein diet can be improved by preventing ammonia toxicity to embryo through NCG supplementation.

The early development of bovine embryo relies on uterine secretions until implantation, while deviations in the uterine environment can be detrimental to development and survival of embryo [23]. In the early embryo development, leukemia inhibitory factor plays an essential role [24]. One of the initial events during embryo implantation is adhesion of trophoblast cells to glycoproteins in the extra cellular matrix of the uterine epithelium (fibronectin, vitronectin and laminin). Leukemia inhibitory factor promoted the adhesion of extravillous 
trophoblast to fibronectin, vitronectin and laminin during the first trimester of pregnancy [25]. Dietary ARG supplementation could improve embryo implantation in pregnant rats and exhibited an increase in embryonic survival and litter size [26].

Interestingly, supplementation of NCG enhanced pregnancy rates in rats through activation of the phosphatidylinositol 3-kinase/protein kinase $\mathrm{B} /$ mammalian target of rapamycin signaling pathway [27]. The NO and polyamines are key regulators of angiogenesis and embryogenesis, as well as placental and fetal growth [28]. High milk production and improved conception rates are important to dairy producers. Collectively, these studies provide evidence that reproductive efficiency in ruminant can be enhanced via supplementation of targeted nutrients such as ARG or NCG.

\section{On fetus during late pregnancy}

Normally, ewes can give birth to one to three lambs. Multiple pregnancies increase the risk for fetal and neonatal death in ewes, while uterine capacity is a major factor inhibiting fetal survival and growth in mammals [29]. This maternal constraint is particularly evident in pregnant ewes with multiple fetuses, since nutrients and space to nurture all fetuses can not be adequately met, and consequently birth weights and survival rates of lambs are reduced resulting in intrauterine growth restriction (IUGR) [29,30]. However, no treatments have been currently used to prevent IUGR in sheep from gestating multiple fetuses.

As a common precursor for synthesis of $\mathrm{NO}$ and polyamines, ARG is crucial for placental angiogenesis and growth in mammals [31]. Therefore, alterations in the ARG-NO and polyamine pathways are contributed to impaired utero-placental blood flow and IUGR in animals. There is evidence that ARG enhanced fetal growth in ewes by serving IUGR carrying quadruplets [7]. Proper developments of the placenta are critical for a successful pregnancy [32], while vasculogenesis and angiogenesis are critical for both proper placental function and normal embryonic/fetal growth and development [32,33].

Generally, the angiogenic process is initiated by growth factors such as vascular endothelial growth factor (VEGF) and placental growth factor 1 [33]. The VEGF is considered to be the most important factor promoting the differentiation of mesenchymal cells in the villous core into hemangioblastic stem cells and is mostly known to regulate the processes of vasculogenesis and angiogenesis [32]. As a potent endothelial survival factor, VEGF induces vasodilation and facilitates blood flow by increased NO production, and is considered as potential promoter of endothelial permeability [34]. Through elevated endothelial NO synthase in placental surface vessels and increased nutrients supply to fetus, NCG may improve litter size and fetal survival [35]. It has been demonstrated that dietary supplementation of ARG or NCG affect microRNAs (miR-15b, miR-222) targeting VEGFA and endothelial NO synthase gene expressions in umbilical vein, consequently regulate the function and volume of the umbilical vein, provide more nutrients and oxygen from the maternal to the fetus tissue [36]. Therefore, supplementation of NCG during late pregnancy to ruminant animals is an effective strategy for fetal development and survival.

\section{Effect of NCG on growth and cell proliferation Body homeostasis by increasing brown adipose tissue} Healthy newborn calves, lambs and kids provide foundation for profitable dairy enterprises. Unfortunately, neonatal mortality remains a significant problem worldwide. Many newborn, particularly lambs and kids, die during winter season due to body heat loss rather than disease. The rate of heat loss is affected by several factors, the most important one of which is to maintain body temperature when livestock exposed to cold environments where oxidation of nutrients and body reserves will be used to generate heat. In sheep, fetal brown adipose tissues, main fat reserves oxidized for heat, start to be generated after mid-gestation [37,38]. Flyn and Wu [39] demonstrated that endogenous synthesis of ARG played an important role to maintain ARG homeostasis in neonatal pig and weaned piglets. Decreased maternal obesity and multiple advantages of fetal growth (organ and tissues development and fetal brown adipose tissue enhancement) were also induced by supplementation of ARG [40]. Therefore, supplementation of NCG to sheep and goat could be best way to increased plasma ARG concentration in specific period of pregnancy during winter season could maintain the homeostasis of neonate and prevent the mortality and consequently improve productivity and profitability of ruminant animals.

\section{Weaned weight and growth}

Minimizing the stress during weaning ensures the calves to continue production process. Before weaning, calves are highly susceptible to gastrointestinal disorders, especially diarrhea. Weaning is a stressful event in the calf's lifetime with alterations in behavior [41], and immune function [42]. Dietary supplementation of NCG could enhance intestinal growth and mRNA abundance of heat shock protein, prevent intestinal dysfunction and ameliorated stress induced by weaning, and improve growth performance in weanling pig [43]. Additionally, ARG is the most abundant $\mathrm{N}$ carrier in tissue protein and may be responsible for maximal growth of young mammals [44]. The plasma ARG and somatotropin levels were increased by oral supplementation of NCG, and growth rate and muscle protein synthesis was improved in 
nursing piglets [10]. Supplementation of NCG increased the proliferating cell nuclear antigen mRNA and induced cell growth and proliferation in intestinal mucosa, thus improved intestinal mucosa morphology in weaning piglets [45]. Weaning weight and plasma ARG concentrations were greater when calves received an ARG supplemented ration [46]. It is reported that dietary supplementation with $1.0 \%$ glutamate prevented weaning-induced villus atrophy in jejunum of weanling piglets, and combined supplementation of glutamate and NCG had favorable effect on intestinal epithelium cell proliferation and prevented intestinal mucosa dysfunction [47]. It is inferred that feeding NCG to calves and lambs during weaning stage could decreases the stress, enhance immunity and weight gain, and consequently improve animal productity and profitability.

\section{Significance of NCG in lactation and N utilization Lactation performance}

Managing high producing cows has always been challenge for dairy farmers and nutritionists. As a precursor of $\mathrm{NO}$, ARG has caused great interest due to the potential role of $\mathrm{NO}$ in regulating mammary tissue nutrient perfusion [48]. Increased amount of nutrients available to mammary glands is critical to enhance AA uptake for milk production [49]. Thus, the number of mammary cells and the amount of available nutrients are the dominant factors for milk production.

It has been showed that ARG increased milk production in cattle and growth hormone in heifers $[4,5]$. However, mechanism of improved milk production induced by ARG needs to be elucidated. On other hand, high yielding animals need diet containing high protein for maximum production that consequently causes the ammonia toxicity and decreased feed intake [50], whereas Lobley et al. [51] reported that ureagenesis may compete with other process that alters AA required for milk synthesis. It is well recognized that ARG plays a key role in ureagenesis [3]. In our preliminary study [18] feeding NCG to high yielding dairy cows significantly decreased the plasma ammonia $\mathrm{N}$ and increased NO concentration compared to control. Yield of milk and milk protein and contents of milk protein and lactose were also increased.

\section{Nitrogen utilization}

Dairy animals are inefficient in $\mathrm{N}$ conversion, and only $25 \%-30 \%$ of dietary $\mathrm{N}$ can be converted into milk [52]. Formulation of low $\mathrm{N}$ diet can be efficient approach to reduce $\mathrm{N}$ excretion, but decreased milk production [53], particularly in high yielding cows. Alternatively, $\mathrm{N}$ utilization can be improved by increased conversion rate of intake protein [54], increased urea recycling in gut and liver and optimized AA balance [11]. Oba et al. [11] confirmed that rumen epithelial cells and duodenal cells had the capacity to utilize the NCG for urea N recycling if CPS1 enzyme activity is stimulated. Thus, urea synthesis in gut tissues could provide a potential target to decrease ammonia absorption and improve $\mathrm{N}$ utilization in ruminant [55]. In our current study, supplementation of $20 \mathrm{~g} / \mathrm{d}$ NCG to high yielding dairy cows significantly decreased the urea $\mathrm{N}$ excretion in milk, plasma and urine, while the $\mathrm{N}$ utilization tended to be improved [18], indicating that feeding NCG to high yielding dairy cows in early to mid lactation is an effective strategy to improved the $\mathrm{N}$ utilization.

\section{Conclusions}

The NCG has been potentially substituted for ARG in non-ruminant animal. Lower rumen degradation of NCG has made it cheaper compared to ARG in ruminant industry. Supplementation of NCG to high yielding cows can increase plasma ARG concentration and milk production. The $\mathrm{N}$ utilization and reproductive efficiency in ruminant can be enhanced by supplementation of NCG, indicating that NCG may be a novel feed additives for ruminant that could not only substitute of ARG, but has some beneficial effect on $\mathrm{N}$ utilization. Further studies should be conducted to see the effect of NCG on metabolic mechanism, growth and reproductive performance of ruminant animals.

\section{Abbreviations}

ARG: Arginine; CPSI: Carbamoyl phosphate synthetase1; IUGR: Intrauterine growth restriction; N: Nitrogen; NAG: N-acetyl glutamate; NCG: N-carbamoyl glutmate; NO: Nitric oxide; P5C: Pyrroline-5-carboxylate; VEGF: Vascular endothelial growth factor.

\section{Competing interests}

The authors declare that they have no competing interests.

\section{Authors' contributions}

$\mathrm{BC}$ collected the information used in manuscript, and drafted and revised the manuscript. HYL collected the information and helped to draft the manuscript. DMW checked the language and grammar of the manuscript. $J X L$ participated in concept designing the manuscript and critically revised the manuscript. All authors made substantial inputs to the review and approved the final manuscript.

\section{Acknowledgements}

This research was supported by China Agriculture Research System (No. CARS-37). BC is the recipient of Scholarship from Zhejiang University, P.R. China.

Received: 5 February 2013 Accepted: 7 April 2013

Published: 10 April 2013

\section{References}

1. Morris SM Jr: Recent advance in arginine metabolism: roles and regulation of arginases. Br J Phar 2009, 157(6):922-930.

2. National Research Council: Nutrient requirements of dairy cattle. Seventh Revised Editionth edition. Washington, DC: National Academy Press; 2001.

3. Meijer AJ, Lof C, Ramos IC, Verhoeven AJ: Control of ureogenesis. Eur J Biochem 1985, 148(1):189-196.

4. Davenport GM, Boling JA, Schillo KK: Nitrogen metabolism and somatotropin secretion in beef heifers receiving abomasal arginine infusions. J Anim Sci 1990, 68(6):1683-1692. 
5. Chew BP, Eisenman JR, Tanaka TS: Arginine infusion stimulates prolactin, growth hormone, insulin, and subsequent lactation in pregnant dairy cows. J Dairy Sci 1984, 67(11):2507-12518.

6. Lassala A, Bazer FW, Cudd TA, Datta S, Keisler DH, Satterfield MC, Spencer TE, Wu G: Parenteral administration of L-arginine prevents fetal growth restriction in undernourished ewes. J Nutr 2010, 140(7):1242-1248.

7. Lassala A, Bazer FW, Cudd TA, Datta S, Keisler DH, Satterfield MC, Spencer TE, Wu G: Parenteral administration of L-arginine enhances fetal survival and growth in sheep carrying multiple fetuses. J Nutr 2011, 141(5):849-855.

8. Chacher B, Wang DM, Liu HY, Liu JX: Degradation of L-arginine and Ncarbamoyl glutamate and their effect on rumen fermentation in vitro. Ital J Anim Sci 2012, 1:e68:374-377.

9. Gessler P, Buchal P, Schwenk HU, Wermuth B: Favourable long-term outcome after immediate treatment of neonatal hyperammonemia due to N-acetylglutamate synthase deficiency. Eur J Pediatr 2010, 169(2):197-199.

10. Frank J, Escobar J, Nguyen HV, Scott C, Jobgen HC, Jobgen WC, Davis TA, WU G: Oral N-carbamylglutamate supplementation increases protein synthesis in skeletal muscle of piglets. J Nutr 2007, 137(2):315-319.

11. Oba M, Baldwin LR, Owens SL, Bequette BJ: Metabolic fate of ammonia N in ruminal epithelial and duodenal mucosal cells isolated from growing sheep. J Dairy Sci 2005, 88(11):3963-3970.

12. Castillo L, Chapman TE, Yu YM, Ajami A, Burke JF, Young VR: Dietary arginine uptake by the splanchnic region in adult humans. Am J Physiol Endocrinol Metab 1993, 265(4):E532-E539.

13. Wu G, Knabe DA, Kim SW: Arginine nutrition in neonatal pigs. J Nutr 2004, 134:2783S-2790S.

14. Daniotti M, Marca GL, Fiorini P, Filippiet $L$ : New developments in the treatment of hyperammonemia: emerging use of carglumic acid. Inter J Genrl Med 2011, 4:21-28.

15. Hall LM, Metzenberg RL, Cohen PP: Isolation and characterization of a naturally occurring cofactor of carbamyl phosphate biosynthesis. J Biol Chem 1958, 230(2):1013-1021.

16. Wu G, Morris SM Jr: Arginine metabolism: nitric oxide and beyond. Biochem J 1998, 336:1-17.

17. O'Connor JE, Jorda A, Grisolia S: Acute and chronic effects of carbamyl glutamate on blood urea and ammonia. Eur J Pediatr 1985, 143(3):196-197.

18. Chacher B, Zhu W, Ye JA, Wang DM, Liu JX: Effect of dietary Ncarbamoyl glutamate on milk production and nitrogen utilization in high yielding dairy cows (abstract \# 56069) accepted for JAM. Indianapolis, USA: ADSA-ASAS; 2013.

19. Lucy MC: ADSA foundation scholar award: reproductive loss in highproducing dairy cattle: where will it end? J Dairy Sci 2001, 84:1277-1293.

20. Ferguson JD, Blanchard T, Galligan DT, Hoshall DC, Chalupa W: Infertility in dairy cattle fed a high percentage of protein degradable in the rumen. JAVMA 1988, 192(5):659-661.

21. Hammon DS, Holyoak GR, Dhiman TR: Association between blood plasma urea nitrogen levels and reproductive fluid urea nitrogen and ammonia concentrations in early lactation dairy cows. Anim Reprod Sci 2005 86(3-4):195-204

22. Ah Mew N, ter McCar R, Daikhin Y, Nissim I, Yudkoff M: Tuchman M:Ncarbamylglutamate augments ureagenesis and reduces ammonia and glutamine in propionic acidemia. Pediatrics 2010, 126(1):e208-e214

23. Wiebold $J$ : Embryonic mortality and the uterine environment in firstservice lactating dairy cows. J Reprod Fertil 1988, 84(2):393-399.

24. Stewart CL, Kaspar P, Brunet J, Bhatt H, Gadi I, Köntgen F, Abbondazo S: Blastocyst implantation depends on maternal expression of leukaemia inhibitory factor. Nat 1992, 359(6390):76-79.

25. Tapia A, Salamonsen LA, Manuelpillai U, Dimitriadis E: Leukemia inhibitory factor promotes human first trimester extravillous trophoblast adhesion to extracellular matrix and secretion of tissue inhibitor of metalloproteinases-1 and -2. Hum Reprod 2008, 23(8):1724-1732.

26. Zeng XF, Wang F, Fan X, Yang W, Zhou B, Li P, Yin Y, Wu G, Wang J: Dietary arginine supplementation during early pregnancy enhances embryonic survival in rats. J Nutr 2008, 138(8):1421-1425.

27. Zeng X, Huang Z, Mao X, Wang J, Wu G, Qiao S: N-carbamoyl glutmate enhances pregnancy outcome in rats through activation of PI3K/PKB/ mTOR signaling pathway. PLoS One 2012, 7(7):e 41192

doi:10.1371.journal.pone.0041192y.
28. Wu G, Bazer FW, Cudd TA, Meininger CJ, Spencer TE: Maternal nutrition and fetal development. J Nutr 2004, 134(9):2169-2172.

29. Gootwine E, Spencer TE, Bazer FW: Litter-size-dependent intrauterine growth restriction in sheep. Animal 2007, 1(4):547-564.

30. Gluckman PD, Hanson MA: Maternal constraint of fetal growth and its consequences. Semin Fetal Neonatal Med 2004, 9(5):419-425.

31. Sheppard C, Shaw CE, Li Y, Bird IM, Magness RR: Endothelium-derived nitric oxide synthase protein expression in ovine placental arteries. Biol Reprod 2001, 64(5):1494-1499.

32. Arroyo JA, Winn VD: Vasculogenesis and angiogenesis in the IUGR placenta. Semin Perinatol 2008, 32(3):172-177.

33. Zygmunt M, Herr F, Munstedt K, Lang U, Liang OD: Angiogenesis and vasculogenesis in pregnancy. Eur J Obstet Gynecol Reprod Biol 2003, 110(Suppl. 1):S10-S18.

34. Valdes G, Corthorn J: Review: the angiogenic and vasodilator uteroplacental network. Placenta 2011, 32(Suppl. 2):S170-S175.

35. Wu X, Yin YL, Liu YQ, Liu XD, Liu ZQ, Li TJ, Huanga RL, Ruan Z, Deng ZY: Effect of dietary arginine and $\mathrm{N}$-carbamoyl glutamate supplementation on reproduction and gene expression of eNOS, VEGFA and PIGF1 in placenta in late pregnancy of sows. Animal Repro Sci 2012, 132(3-4):187-192.

36. Liu XD, Wu X, Yin YL, Liu YQ, Geng MM, Yang HS, Francois B, Wu GY: Effects of dietary-arginine or $\mathrm{N}$-carbamylglutamate supplementation during late gestation of sows on the miR-15b/16, miR-221/222, VEGFA and eNOS expression in umbilical vein. Amino Acids 2012, 42:2111-2119.

37. Symonds ME, Mostyn A, Pearce S, Budge H, Stephenson T: Endocrine and nutritional regulation of fetal adipose tissue development. J Endocrinol 2003, 179(3):293-299.

38. Cannon B, Nedergaard J: Brown adipose tissue: function and physiological significance. Physiol Rev 2004, 84(1):277-359.

39. Flynn NE, Wu G: An important role for endogenous synthesis of arginine in maintaining arginine homeostasis in neonatal pigs. Am J Physiol 1996, 271(5pt)):R1149-R1155

40. Satterfield MC, Dunlap KA, Keisler DH, Bazer FW, Wu G: Arginine nutrition and fetal brown adipose tissue development in diet-induced obese sheep. Amino Acids 2012, 43(43):1593-1603.

41. Enríquez D, Hötzel MJ, Ungerfeld R: Minimizing the stress of weaning of beef calves: a review. Acta Vet Scand 2011, 53:1-8. doi:10.1186/1751-0147-53-28.

42. Arthington DJ, Qui $X$, Cooke RF, Vendramini JMB, Araujo DB, Chase CC Jr, Coleman SW: Effects of preshipping management on measures of stress and performance of beef steers during feedlot receiving. J Anim Sci 2008, 86(8):2016-2023.

43. Wu X, Yin YL, Li TJ, Wang L, Ruan Z, Liu ZQ, Hou YQ: Dietary supplementation with $\mathrm{L}$-arginine or $\mathrm{N}$-carbamylglutamate enhances intestinal growth and heat shock protein-70 expression in weanling pigs fed a corn- and soybean meal-based diet. Amino Acids 2010, 39(3):831-839.

44. Flynn NE, Meininger CJ, Haynes TE, Wu G: The metabolic basis of arginine nutrition and pharmacotherapy. Biomed Pharmacother 2002, 56(9):427-438

45. Ying P: Effect of oral supplementation with $\mathrm{N}$-carbamoly glutmate on serum biochemical indices and intestinal morphology with its proliferation in weaning piglets. J Anim Vet Adv 2012, 11:2926-2929.

46. Fligger JM, Gibson CA, Sordillo LM, Baumrucker CR: Arginine supplementation increases weight gain, depresses antibody production, and alters circulating leukocyte profiles in preruminant calves without affecting plasma growth hormone concentrations. J Anim Sci 1997, 75(11):3019-2.

47. Wu X, Zhang Y, Liu Z, Li TJ, Yin YL: Effects of oral supplementation with glutamate or combination of glutamate and $\mathrm{N}$-carbamylglutamate on intestinal mucosa morphology and epithelium cell proliferation in weanling piglets. J Anim Sci 2012, 90:337-339

48. Lacasse P, Farr VC, Davis SR, Prosser CG: Local secretion of nitric oxide and the control of mammary blood flow. J Dairy Sci 1996, 79(2):1369.

49. Guan X, Bequette BJ, Calder G, Ku PK, Ames KN, Trottier NL: Amino acid availability affects amino acid transport and protein metabolism in the porcine mammary gland. J Nutr 2002, 132(6):1224-1234.

50. Bachman C, Colombo JP, Jaggi K: N-acetylglutamate synthetase (NAGS) deficiency: diagnosis, clinical observation and treatment. Adv Exp Med Biol 1982, 153:313-319. 
51. Lobley GE, Connell A, Lomax MA, Brown DS, Milne EA, Calder G,

Farningham DAH: Hepatic detoxification of ammonia in the ovine liver: possible consequences for amino acid catabolism. Br J Nutr 1995, 73(5):667-685.

52. Tamminga S: Nutrition management of dairy cows as a contribution to pollution control. J Dairy Sci 1992, 75(1):345-357.

53. Broderick GA: Effects of carrying dietary protein and energy levels on the production of lactating dairy cows. J Dairy Sci 2003, 86(4):1370-1381.

54. Noftsger S, St-Pierre NR: Supplementation of methionine and selection of highly digestible rumen undegradable protein to improve nitrogen efficiency for milk production 1. J Dairy Sci 2003, 86(3):958-969.

55. Marini JC, Van Amburgh ME: Nitrogen metabolism and recycling in Holstein heifers. J Anim Sci 2003, 81(2):545-552.

doi:10.1186/2049-1891-4-16

Cite this article as: Chacher et al:: Potential role of $\mathrm{N}$-carbamoyl glutamate in biosynthesis of arginine and its significance

in production of ruminant animals. Journal of Animal Science and Biotechnology 2013 4:16.

\section{Submit your next manuscript to BioMed Central and take full advantage of:}

- Convenient online submission

- Thorough peer review

- No space constraints or color figure charges

- Immediate publication on acceptance

- Inclusion in PubMed, CAS, Scopus and Google Scholar

- Research which is freely available for redistribution 